\title{
Relevance of sink-size estimation for within-field zone delineation in vineyards
}

\author{
Urretavizcaya, I. (a); Royo, J.B. (a); Miranda, C. (a); Tisseyre, B. (b); Guillaume, S.(b); Santesteban, L.G. (a)
}

a Departamento de Producción Agraria, Universidad Pública de Navarra, Pamplona, Navarre, Spain

b UMR ITAP, IRSTEA/Montpellier SupAgro, Montpellier, France

\begin{abstract}
Source to sink size ratio, i.e.: the relative abundance of photosynthetically active organs (leaves) with regards to photosynthate demanding organs (mainly bunches), is widely known to be one of the main drivers of grape oenological quality. However, due to the difficulty of remote sink size estimation, Precision Viticulture (PV) has been mainly based on within-field zone delineation using vegetation indices. This approach has given only moderately satisfactory results for discriminating zones with differential quality. The aim of this work was to investigate an approach to delineate within-vineyard quality zones that includes an estimator of sink size in the data-set. The study was carried out during two consecutive seasons on a 4.2 ha gobelet-trained cv. 'Tempranillo' vineyard. Zone delineation was performed using Normalized Difference Vegetation Index (NDVI), soil apparent electrical conductivity $\left(\mathrm{EC}_{\mathrm{a}}\right)$ and bunch number $(\mathrm{BN})$ data. These variables were considered separately, in pairs, or the three altogether, using fuzzy $k$-means cluster analysis for combinations. The zones delineated based on single variables did not allow a sufficient discrimination for grape composition at harvest, NDVI being the only variable that by itself resulted in zones that to some extent differed in grape composition. On the contrary, when two variables were combined, discrimination in terms of grape composition improved remarkably, provided the sink size estimation variable (BN) was included in the combination. Lastly, the combination of the three variables yielded the best discriminating zoning, improving slightly on those provided by NDVI+BN and $\mathrm{EC}_{\mathrm{a}}+\mathrm{BN}$ combinations. Thus, the relevance of including a variable related to sink size (in this case the number of bunches per plant) has been confirmed, which makes its consideration highly advisable for any PV work aiming at zone delineation for grape quality purposes.
\end{abstract}

\section{Introduction}

The delineation of within-vineyard zones that would potentially produce grapes of differential quality has been one of the main aspects that Precision Viticulture (PV) has dealt with in the last decade. Zone delineation has been based mainly on the information given by remotely obtained vegetative indices, and has been proved to be suitable to distinguish zones within the vineyard with different vegetative development (Santesteban et al. 2010; AcevedoOpazo et al. 2008a; Acevedo-Opazo et al. 2008b; Acevedo-Opazo et al. 2010; Hall et al. 2003; Bramley et al. 2011c). However, the performance of this approach with regards to grape composition is much more erratic. For instance, Bramley et al. (2011b) used PCD index to delineate zones, observing oenological differences for just two of the five wine composition parameters considered. Similarly, Acevedo-Opazo et al. (2008a) found that the zones defined with NDVI were not coherent with most grape composition parameters, and Santesteban et al. (2010) only found differences between NDVI-defined zones for one of the six grape composition parameters considered. On the contrary, Hall et al. (2011), observed that grape 
composition was generally correlated with vegetation indices, although the correlation coefficients found were inferior to 0.4 . King et al. (2004) reported a very good correspondence between the zones defined with NDVI obtained with a proximal sensor mounted to an allterrain vehicle and grape composition.

The zone delineation process has been completed by some authors combining the information given by vegetation indices with other variables such as soil apparent electric conductivity $\left(\mathrm{EC}_{\mathrm{a}}\right.$ ) or elevation (Bramley et al. 2011a; Bramley and Lamb 2003; Corwin and Lesch 2005; Santesteban et al. 2013; Urretavizcaya et al. 2011; Tagarakis et al. 2013), but the degree of agreement between the zones defined and grape composition was still just moderate. Santesteban et al. (2013) hypothesised that introducing any variable that estimated sink size (i.e.: fruit load) in multivariate based methods for zone delineation would provide an improvement in their performance, since an adequate balance between photosynthate sources (leaves) and sinks (majorly the bunches) is known to determine, to a great extent, grape quality (Howell 2001).

The balance between source and sink size has been classically estimated by the Ravaz Index, defined as the ratio between grape and pruning wood mass (Ravaz 1903) and constitutes one of the most widely used indices among viticulturists. More recently, the ratio between leaf area and the amount of fruit has been introduced as an index to estimate vineyard balance (Howell 2001) and is frequently referred as crop load. In opposition to the relevance that has been given to vine balance in classic viticulture, PV has only taken into account "source size", since vegetation indices are good surrogates for leaf area development (Baluja et al. 2012; Hall et al. 2011; Johnson et al. 2003; Tagarakis et al. 2013) and can, to some extent, represent canopy microclimate as canopy size conditions it (Smart and Robinson 1991), but are not good surrogates of the amount of fruit (Hall et al. 2011; Bonilla et al. 2015). The main reason for not considering "sink size" relative variables for zone delineation is probably that, to date, there is not a readily usable method that would allow the estimation of its spatial variability. Nevertheless, there is a growing interest in developing methods for accurate and cost effective estimation of fruit load early in the season, based on RGB (red, green and blue) and multispectral imagery (Diago et al. 2012; Nuske et al. 2011; Fernandez et al. 2013). In that sense, the work performed by Grocholsky et al. (2011), where both sink and source sizes were simultaneously estimated using a camera and laser system, is particularly relevant. The inclusion of sink size estimators for within zone delineation will have a great impact for vineyard management (for example, adjusting cultural practices to get more balanced vines by practices such as cluster or leaf thinning)

The aim of this work was to investigate an approach to delineate within-vineyard grape quality zones from information obtained earlier in the season. The originality of this approach is the inclusion of an estimator of sink size in the data-set. 


\section{Materials and methods}

\section{Experimental layout}

The study was carried out during two consecutive seasons (2010 and 2011) on a 4.2 ha gobelet-trained cv. 'Tempranillo' vineyard, located in Leza (42 33' 22" N, 2 $38^{\prime}$ 07' W, $572 \mathrm{~m}$ asl, Basque Country, Spain). The vineyard was 17 -years old at the beginning of the experiment, with a $2.4 \times 1.2 \mathrm{~m}$ planting distance and no irrigation system, as this is a traditionally rain-fed vineyard area. This climate of the area belongs to Classes II and III in Huglin's classification (Huglin and Schneider 1998). The climatic conditions in 2010 were drier and warmer than average, whereas in 2011 the weather was similar to average in terms of spring rainfall, and slightly cooler in temperature, but the lack of rainfall from mid-August to late-September led to moderate water deficit and basal defoliation after NDVI image acquisition. More detailed data on the climatic conditions during the study period and some vineyard characteristics are detailed in Urretavizcaya et al. (2014).

During the season previous to the start of the experiment (2009), Normalized Differential Vegetative Index (NDVI) information was obtained from QuickBird satellite images, taken shortly after veraison (first half of August). Pixel size is $0.61 \mathrm{~m}$ for panchromatic, and 2.4 meter for multispectral. NDVI was used to define a field sampling grid. The distance between each sampling point (SP) of the grid was chosen as the range of the NDVI semi-variogram model corresponding to $25 \%$ of the total semi variance (CO + C1), which implies that $75 \%$ of spatial variability was encompassed. The resulting sampling grid consisted of $60 \mathrm{SP}$, with a 30 $\mathrm{m} \times 30 \mathrm{~m}$ distance between them. At each SP, 15 adjacent plants located in three consecutive rows were marked, and all of them were used for the experimental measurements and sampling.

In order to delineate within-vineyard zones, information related to (i) vegetative development, (ii) sink size and (iii) soil characteristics were considered.

- Vegetative development was estimated using the NDVI calculated from QuickBird multiband satellite images acquired shortly after veraison each year, once vegetative growth had stopped. Once a map for the whole vineyard was obtained, the average value observed at the pixels in the zone that included the 15 vines at each SP was calculated and assigned to it. In order to test the ability of NDVI to estimate vegetative development in goblelet trained vines, for which no references are available, mean total shoot cross sectional area (SCSA) was calculated for each SP by measuring the basal diameter of all the shoots in the 15 vines at the end of July, once apical growth was stopped.

- Sink size was estimated by counting at veraison the total number of bunches (BN) of all the 15 vines at each SP. 
- Soil variability was characterized by measuring soil electrical apparent conductivity $\left(E C_{a}\right)$ at each SP using a handheld EM38 (Geonics Ltd, Ontario, Canada). At each sampling point, EC $\mathrm{a}_{\mathrm{a}}$ measurements were performed every second for 3-5 minutes, and the obtained data averaged after removing values shown to be outliers in box-and-whisker diagram. The measurements were performed in 2010 winter, after a heavy rainfall, in order to minimize the differences between measurements caused by soil water content.

The evaluation of the agronomic significance of the zones delineated was tested using yield and grape composition data obtained at harvest. Yield was determined by weighting all the bunches produced by the 15 vines at each SP. Then, a 300-berry sample was gathered per $\mathrm{SP}$, and berry weight (BW) as well as the main composition parameters were determined using standard procedures. Shortly, after crushing, total soluble solids concentration (TSS) was measured with a temperature compensating refractometer RFM840 (Bellingham-Stanley Ltd., Kent, UK), pH and titratable acidity (TA) using a pH-Burette 24 auto-titrator (Crison, Barcelona, Spain), malic (MalA) and tartaric acid (TarA) concentration was measured enzymatically using an autoanalyzer (Easychem, Systeas.p.a., Italy), whereas yeast assimilable nitrogen (YAN) was estimated following the procedure described by Aerny (1996) with the modifications detailed in Garcia et al. (2011). Phenolic maturity was evaluated after $4 \mathrm{~h}$ extraction in two different media ( $\mathrm{pH}=1.0, \mathrm{pH}=3.2$ ) following the methodology described in Glories and Augustin (1993) that allows estimating the concentration of total (TAnt) and extractable (EAnt) anthocyanins and of total phenolics (TP).

\section{$\underline{\text { Data analysis }}$}

For both years of the experiment, the $60 \mathrm{SP}$ were classified considering three clustering variables (NDVI, $E C_{a}$ and $B N$ ) and their possible combinations. Classes (i.e: clusters) were defined through fuzzy $k$-means analysis. The potential number of classes was considered to be 2, 3 and 4, and the best-performing number was chosen taking into account the values obtained for fuzziness performance index (FPI) and modified partition entropy (MPE) (Boydell and McBratney 2002) for fuzzy exponents ranging from 1.0 to 1.9. Clustering was performed applying fuzzy $k$-means analysis to pixel values in NDVI, $\mathrm{EC}_{\mathrm{a}}$ and $\mathrm{BN}$ maps, obtained using ordinary kriging as detailed in Urretavizcaya et al. (2014)

The oenological significance of the classes defined was evaluated with two different procedures, using yield, berry weight and the nine grape composition variables measured at harvest (TSS, pH, TA, MalA, TarA, YAN, TAnt, EAnt and TP). Firstly, a one-way ANOVA considering the classes as the factor was used, allowing a separated evaluation for each variable. When the ANOVA showed statistically significant differences $(P<0.05)$, a TukeyKramer's test to determine post hoc separation between means was used, as it is a test suitable for unbalanced data sets (Sahai and Ojeda 2004). Secondly, MANOVA was done with the nine grape composition variables, considering as factors the classes defined by the seven input data (NDVI, EC a and BN, and their four possible combinations). ANOVAs were performed using IBM SPSS Statistics v.21 (IBM SPSS Statistics Inc., Chicago, IL), and MANOVAs with R (v. 3.1.0, the R Foundation for Statistical Computing). 


\section{Results and discussion}

\section{Significance of NDVI measurements in gobelet trained vines}

NDVI was shown to be a good estimator of vegetative development in goblelet trained vines, since it was related to total shoot cross sectional area (SCSA) measured at the end of July in 2010, when apical growth was already stopped (SCSA $=122.9+1722.6 * \mathrm{NDVI}, \mathrm{R}^{2}=0.58$, Fig 1). Although there were no earlier references on the performance of NDVI as a vegetative development surrogate in gobelet trained vines, it was reasonable to consider its usefulness since, some of NDVI limitations in vertical shoot positioned (VSP) canopies such as narrow canopies that create problems with aerial and satellite sensing (Taylor et al. 2005) or saturation effect of red NDVI when the canopies are big (Stamatiadis et al. 2010) apply to a much lower extent in a free-trained system.

\section{Within-vineyard variability for grape composition}

The average values observed for quality parameters were relatively similar in the two seasons considered (Table 1 ), the main differences being observed for TSS ( 25.2 vs. $24.0^{\circ}$ Brix) and MalA ( 2.80 vs. $1.87 \mathrm{~g} \mathrm{~L}^{-1}$ ), as similarly reported by Baluja et al. (2013) for the same seasons for cv. Tempranillo, in a nearby area. The reason behind these differences may be that during the last part of the season in 2011, moderate to severe water deficit occurred across the vineyard, which resulted in a considerable basal shoot defoliation that probably implied a reduction coupled to a decrease in photosynthetic activity (Tomás et al. 2012) and an increase in malic acid degradation (De Souza et al. 2005).

As a whole, the range and variability observed for grape composition parameters was high (Table 1), particularly for TSS, YAN, and for all parameters related to phenolic maturity (TAnt, EAnt and TP), for which nearly two-fold differences were observed between the lowest and the highest values each season. On the contrary, a much lower range was observed for must acidity (TA, MalA, TarA), for which the difference between the highest and lowest values within the same year was $\approx 1 \mathrm{~g} \mathrm{~L}^{-1}$. The range of variability of grape composition within this vineyard can be therefore considered large enough to justify grape segregation into batches with different quality and, as a consequence, a good target vineyard for PV implementation. The SP with higher anthocyanin and phenolics concentrations would be suitable for aged wines, those within the lower range would have been suitable only for generic wine. Similarly, grapes within the lower range of soluble solids content would have benefited from a later harvest to reach TSS $>23.5^{\circ} \mathrm{Brix}$, the threshold for harvesting in the region. CV values were between $1 / 2$ and $1 / 3$ of the $C V$ values observed during the same year in samples taken from a network of $74 \mathrm{cv}$. Tempranillo vineyards in the same area (data not shown), which gives an idea of the the magnitude of the variability in grape composition that can be found within a single vineyard. 


\section{Significance of the zones defined}

The zones delineated with the 7 different input data, i.e. NDVI, EC $\mathrm{a}_{\mathrm{a}} \mathrm{BN}$ and their combinations (Fig. 2), showed a very different performance when the agronomic significance of the classes was evaluated through ANOVA analyses of yield and the grape composition parameters obtained at harvest. Results are summarized in Table 2, and given in detail as Supplementary Material in Table S1. The zones delineated when NDVI, EC a and BN were considered individually performed poorly: NDVI was the single variable that allowed the differentiation between classes for more grape composition variables (4 in 2010, 4 in 2011), whereas the classes defined solely with $\mathrm{EC}_{\mathrm{a}}$ discriminated for none of the grape composition parameters, and BN discriminated for only 1 parameter in 2010 and for 2 in 2012. Quite surprisingly, BN classification performed poorly even for yield and BW discrimination, only being able to discriminate classes with different yield and BW in 2010. BN plays only a moderate role in yield definition, which is more closely relatedo to berry number (Dunn and Martin 1998).

However, the classifications obtained by fuzzy $k$-means analysis when combining two out of the three variable clustering variables considered (NDVI+BN, $E C_{a}+B N$ and $N D V I+E C_{a}$ ) performed much better (Table 2). The classification that included the three variables $\left(\mathrm{NDVI}+\mathrm{EC}_{\mathrm{a}}+\mathrm{BN}\right.$ ) was the best-performing one (discriminated for 5 and 6 grape composition parameters in 2010 and 2011 respectively), followed by NDVI+BN and EC $\mathrm{a}_{\mathrm{a}}+\mathrm{BN}$ (4 and 6 in 2010 and 2011 respectively). These three combinations also allowed discriminating for the two quantitative crop parameters considered (yield and BW) both seasons. The poorest-performing of the three combinations was the one that did not consider $B N\left(N D V I+E C_{a}\right)$, which only discriminated for 1 and 3 grape composition parameters in 2010 and 2011 respectively. Therefore, the inclusion of an easily measurable variable that estimates sink size improved significantly the zone delineation procedure. For all input data combinations the optimum number of classes was 2 or 3 according to FPI and MPE indices (results not shown).

When the discrimination ability for grape composition of the zones delineated was tested according to MANOVA (Table 3), the trend observed with ANOVA was confirmed. NDVI was the only variable that, on its own, discriminated them significantly. The combination of variables resulted in general in an improvement, and particularly the inclusion of BN in the fuzzy $k$-means analysis increased the significance of the differences observed.

As a whole, the results presented clearly demonstrate the importance of using within-field zone delineation procedures that combine variables that are representative for the main factors that condition grape composition This probably explains why zoning performed using a vegetation index as the only information source in previous studies (Santesteban et al. 2010; Acevedo-Opazo et al. 2008a; Acevedo-Opazo et al. 2008b; Acevedo-Opazo et al. 2010; Hall et al. 2003; Bramley 2005) resulted in only a moderate correspondence with grape composition. According to wine managers in the area, the differences in grape composition between the zones delineated with the best performing classifications would justify up to 2.5-fold differences in grape price (from 0.8 to $2 € / \mathrm{kg}$ ), which clearly could lead to segregated harvest. 
Grape ripening is a very complex process, driven by a wide set of factors that directly or indirectly affect it (Champagnol 1984, Jackson and Lombard 1993). Not taking into account any of the most relevant ones (such as the amount of fruit) hinders a good evaluation of grape quality potential. Vegetative development is certainly a relevant parameter for grape quality, since it is related to light interception and also to competition between vegetative and reproductive sinks during ripening (Smart and Robinson 1991) but, according to the results presented, it has been proved not to be -on its own- efficient enough to discriminate zones of different berry composition. Water availability is also one of the factors conditioning differences in grape quality; particularly in areas where summer conditions are dry (Santesteban and Royo 2006). The inclusion of $E C_{a}$ is probably integrating several soil characteristics directly related to soil water holding capacity due to differences in soil texture and depth (Brevik et al. 2006, Friedman 2005), and has been proved to be useful for classification under our study conditions.

Lastly, the relevance of considering a parameter that estimated sink size has been particularly highlighted by the results obtained, since the performance of the classification method using BN performed better than those not considering it. The balance between fruit level and vegetative development is known to be very decisive for grape quality (Howell 2001), and therefore needs to be included for successful zoning. Although pruning, when skilfully performed, does somehow balance source to sink ratios (more fruiting buds are maintained in the more vigorous parts of the vineyard), differences in this balance still occur from year to year and within-vineyard for the same year, which justifies the inclusion of BN for zone delineation. All this supports the hypothesis set up in Santesteban et al. (2013), who considered sink size to be an essential aspect to be considered for classifications. Our results suggest that, although nowadays it is not possible to obtain a fruit-load related parameter remotely, it is worthwhile including it in any PV work aimed at grape quality estimation, since it is not a very time consuming measurement when it has to be done in field. These results support the necessity of developing procedures to estimate fruit load automatically, and highlights the importance of relevant works conducted in order to determine the number and weight of the clusters through artificial vision (Diago et al. 2012; Nuske et al. 2011; Fernandez et al. 2013; Grocholsky et al. 2011).

\section{Conclusion}

The early definition of within vineyard zones combining NDVI, $E C_{a}$ and $B N$ data was successful, since the zones delineated allowed a differentiation of grape batches with different characteristics at harvest. Interestingly, the inclusion of a variable related to sink size (in this case the number of bunches per plant) provided the most efficient classification, which makes its consideration highly advisable for any PV work aimed at zone delineation for grape quality estimation. 


\section{Acknowledgements}

This work was funded by the Dpt. Innovación, Industria \& Empleo of the Government of Navarra (MODELVID, Ref: IIM11879.RI.1), by the Centro para el Desarrollo Tecnológico Industrial-CDTI (Ref: IDI-20100729, co-funded by the European Union ERDF as part of the Operational Programme I+D+i Technology Fund 2007-2013) and by Fundación Fuentes Dutor. The Spanish Ministry of Education funded I.U. stage in SupAgro, Montpellier (EDU/2719/2011). The authors also would like to express their gratitude to the owners and staff in Bodegas Luis Cañas, particularly to M. José Aparicio and Olaya Fernandez, and to Rafael Álvarez (Verdtech Nuevo Campo) for their co-operation and interest.

\section{Bibliography}

Acevedo-Opazo, C., Tisseyre, B., Guillaume, S., \& Ojeda, H. (2008a). The potential of high spatial resolution information to define within-vineyard zones related to vine water status. Precision Agriculture, 9(5), 285-302.

Acevedo-Opazo, C., Tisseyre, B., Ojeda, H., Ortega-Farias, S., \& Guillaume, S. (2008b). Is it possible to assess the spatial variability of vine water status? Journal International des Sciences de la Vigne et du Vin, 42(4), 203-220.

Acevedo-Opazo, C., Tisseyre, B., Taylor, J. A., Ojeda, H., \& Guillaume, S. (2010). A model for the spatial prediction of water status in vines (Vitis vinifera L.) using high resolution ancillary information. Precision Agriculture, 11(4), 358-378.

Aerny, J. (1996). Composés azotés des moûts et des vins. Revue Suisse de Viticulture. (Nitrogencompounds of musts and wines). Arboriculture et Horticulture, 28, 161-165.

Baluja, J., Diago, M. P., Goovaerts, P., \& Tardaguila, J. (2012). Assessment of the spatial varibility of grape anthocyanins using a fluorescence sensor. Relationships with vine vigour and yield. Precision Agriculture, 13, 457-472.

Baluja, J., Tardaguila, J., Ayestaran, B., \& Diago, M. P. (2013). Spatial variability of grape composition in a Tempranillo (Vitis vinifera L.) vineyard over a 3-year survey. Precision Agriculture, 14, 40-58.

Bonilla, I., Martínez de Toda, F \& Martínez-Casasnovas, J. A. (2015). Vine vigor, yield and grape quality assessment by airborne remote sensing over three years: Analysis of unexpected relationships in cv. Tempranillo. Spanish Journal of Agricultural Research, 13(1), 1-8.

Boydell, B., \& McBratney, A. B. (2002). Identifying potential within-field management zones from cotton-yield estimates. Precision Agriculture, 3(1), 9-23.

Bramley, R. G. V. (2005). Understanding variability in winegrape production systems 2 . Within vineyard variation in quality over several vintages. Australian Journal of Grape and Wine Research, 11(1), 33-42.

Bramley, R. G. V., \& Lamb, D. (2003). Marking sense of variability in Australia. In Proc. Internat. Symp. on Precision Viticulture, Ninth Latin American Congr. on Viticulture and Oenology (pp. 35-54).

Bramley, R. G. V., Ouzman, J., \& Boss, P. K. (2011a). Variation in vine vigour, grape yield and vineyard soils and topography as indicators of variation in the chemical composition of 
grapes, wine and wine sensory attributes. Australian Journal of Grape and Wine Research, 17(2), 217-229.

Bramley, R. G. V., Ouzman, J., \& Thornton, C. (2011b). Selective harvesting is a feasible and profitable strategy even when grape and wine production is geared towards large fermentation volumes. Australian Journal of Grape and Wine Research, 17(3), 298-305.

Bramley, R. G. V., Trought, M. C. T., \& Praat, J. P. (2011c). Vineyard variability in Marlborough, New Zealand: Characterising variation in vineyard performance and options for the implementation of Precision Viticulture. Australian Journal of Grape and Wine Research, 17(1), 83-89.

Brevik, E. C., Fenton, T. E., \& Lazari, A. (2006). Soil electrical conductivity as a function of soil water content and implications for soil mapping. Precision Agriculture, 7(6), 393-404.

Corwin, D. L., \& Lesch, S. M. (2005). Apparent soil electrical conductivity measurements in agriculture. Computers and Electronics in Agriculture, 46, 11-43.

Champagnol, F. (1984). Éléments de physiologie de la vigne et de viticulture générale. (Elements of the physiology of the vine and of general viticulture). Champagnol, St-Gély du Fec, France.

De Souza, C. R., Maroco, J. P., Dos Santos, T. P., Rodrigues, M. L., Lopes, C. M., Pereira, J. S., \& Chaves, M. M. (2015). Grape berry metabolism in field-grown grapevines exposed to different irrigation strategies. Vitis, 44, 103-109.

Dunn G.M., Martin S.R. (1998) Optimising vineyard sampling to estimate yield components. The Australian Grapegrower \& Winemaker, 102-107.Diago, M. P., Correa, C., Millan, B., Barreiro, P., Valero, C., \& Tardaguila, J. (2012). Grapevine Yield and Leaf Area Estimation Using Supervised Classification Methodology on RGB Images Taken under Field Conditions. Sensors, 12(12), 16988-17006.

Fernandez, R., Montes, H., Salinas, C., Sarria, J., \& Armada, M. (2013). Combination of RGB and Multispectral Imagery for Discrimination of Cabernet Sauvignon Grapevine Elements. Sensors, 13(6), 7838-7859.

Friedman, S. P. (2005). Soil properties influencing apparent electrical conductivity: a review. Computers and Electronics in Agriculture, 46, 45-70.

Garcia, S., Santesteban, L. G., Miranda, C., \& Royo, J. B. (2011). Variety and storage time affect the compositional changes that occur in grape samples after frozen storage. Australian Journal of Grape and Wine Research, 17(2), 162-168.

Glories, Y., \& Augustin, M. (1993). Maturité phénolique du raisin, conséquences technologiques: applicationaux millésimes 1991 et 1992. (Phenolic ripeness of grapes, technological consequences:application to vintages 1991 and 1992). Journée technique du C.I.V.B.: Actes du colloque, Bordeaux, 56-61.

Grocholsky, B., Nuske, S., Aasted, M., Achar, S., \& Bates, T. (2011). A camera and laser system for automatic vine balance assessment. Paper presented at the American Society of Agricultural and Biological Engineers Annual International Meeting, ASABE 2011, Technical Library.

Hall, A., Lamb, D. W., Holzapfel, B. P., \& Louis, J. P. (2011). Within-season temporal variation in correlations between vineyard canopy and winegrape composition and yield. Precision Agriculture, 12(1), 103-117. 
Hall, A., Louis, J., \& Lamb, D. (2003). Characterising and mapping vineyard canopy using highspatial- resolution aerial multispectral images. Computers and Geosciences, 29(7), 813822.

Howell, G. S. (2001). Sustainable grape productivity and the growth-yield relationship: A review. American Journal of Enology and Viticulture, 52(3), 165-174.

Huglin, P., \& Schneider, C. (1998). Biologie et écologie de la vigne. (Biology and ecology of the vineyard). Paris: Ed. Lavoisier Tec \& Doc.

Jackson, D. I., \& Lombard, P. B. (1993). Environmental and management practices affecting grape composition and wine quality-a review. American Journal of Enology and Viticulture, 44, 409-430.

Johnson, L., Lobitz, B., Arrnstrong, R., Baldy, R.,Weber, E., De Benedictis, J., \& Bosch, D. (1996). Airborne imaging aids vineyard canopy evaluation. California Agriculture, 50, 14-18

King, P. D., Smart, R. E., \& Mcclellan, D. J. (2004). Within-vineyard variability in vine vegetative growth, yield, and fruit and wine composition of Cabernet Sauvignon in Hawke's Bay, New Zealand. Australian Journal of Grape and Wine Research, 20(2), 234-246.

Nuske, S., Achar, S., Bates, T., Narasimhan, S., \& Singh, S. (2011). Yield Estimation in Vineyards by Visual Grape Detection. Paper presented at the IEEE/Rsj International Conference on Intelligent Robots and Systems, 2352-2358

Ravaz, L. (1903). Sur la brunissure de la vigne. Comptes Rendus de l'Academie des Sciences, $136,1276-1278$.

Sahai, H., \& Ojeda, M. M. (2004).Analysis of variance for random models: theory, methods, applications and data analysis. Boston: Birkaüser.

Santesteban, L. G., Guillaume, S., Royo, J. B., \& Tisseyre, B. (2013). Are precision agriculture tools and methods relevant at the whole-vineyard scale? Precision Agriculture, 14, 217.

Santesteban, L. G., Miranda, C., Jiménez, C., Fuentemilla, M., Urretavizcaya, I., Tisseyre, B., et al. (2010). Evaluación del interés del índice NDVI para la delimitación de unidades de manejo diferenciado (UMD) en una explotación vitícola. (Evaluation of the interest of NDVI to identify distinct management units in vineyards). Revista de Teledetección, 33, 11-16.

Santesteban, L. G., Miranda, C., Urretavizcaya, I., \& Royo, J. B. (2012). Carbon isotope ratio of whole berries as an estimator of plant water status in grapevine (Vitis vinifera L.) cv. Tempranillo. Scientia Horticulturae, 146(0), 7-13.

Santesteban, L. G., \& Royo, J. B. (2006). Water status, leaf area and fruit load influence on berry weight and sugar accumulation of cv. 'Tempranillo' under semiarid conditions. Scientia Horticulturae, 109(1), 60-65.

Smart, R. E., \& Robinson, M. (1991). Sunlight into wine. A handbook for winegrape canopy management. Adelaide, Australia: Winetitles.

Stamatiadis, S., Taskos, D., Tsadila, E., Christofides, C., Tsadilas, C., \& Schepers, J. S. (2010). Comparison of passive and active canopy sensors for the estimation of vine biomass production. Precision Agriculture, 11, 306-315.

Tagarakis, A., Liakos, V., Fountas, S., Koundouras, S., \& Gemtos, T. A. (2013). Management zones delineation using fuzzy clustering techniques in grapevines. Precision Agriculture, 14(1), 18-39. 
Taylor, J., Tisseyre, B., \& Praat, J. P. (2005). Bottling good information: mixing tradition and technology in vineyards. Proceedings of FRUTIC 05: Information and Technology for Sustainable Fruit and Vegetable Production, 12-16.

Tomás, M., Medrano, H., Pou, A., Escalona, J. M., Martorell, S., Ribas-Carbó, M., \& Flexas, J. (2012). Water-use efficiency in grapevine cultivars grown under controlled conditions: effects of water stress at the leaf and whole-plant level. Australian Journal of Grape and Wine Research, 18, 164-172.

Urretavizcaya, I., Santesteban, L. G., Echeverría, N., Miranda, C., \& Royo, J. B. (2011). Precision Viticulture tools to manage goblet-trained vineyards in 'Rioja Alavesa'. Paper presented at the 17th International Giesco Symposium, Asti-Alba (Italy).

Urretavizcaya, I., Santesteban, L. G., Tisseyre, B., Guillaume, S., Miranda, C., \& Royo, J. B. (2014). Oenological significance of vineyard management zones delineated using early grape sampling. Precision Agriculture, 15 (1), 111-129. 
Table 1 Descriptive statistics for grape composition parameters in samples gathered at harvest in the whole field

\begin{tabular}{|c|c|c|c|c|c|c|c|c|}
\hline & \multicolumn{2}{|c|}{ Mean } & \multicolumn{2}{|c|}{ Range } & \multicolumn{2}{|c|}{$\mathrm{CV}(\%)$} & \multicolumn{2}{|c|}{ Spread (\%) } \\
\hline & 2010 & 2011 & 2010 & 2011 & 2010 & 2011 & 2010 & 2011 \\
\hline TSS $\left({ }^{\circ}\right.$ Brix $)$ & 25.16 & 24.00 & 23.34-26.52 & 21.8-25.4 & 2.80 & 2.87 & 12.48 & 14.96 \\
\hline pH & 3.50 & 3.55 & $3.38-3.61$ & $3.41-3.69$ & 1.49 & 1.67 & 6.58 & 7.88 \\
\hline $\mathrm{TA}\left(\mathrm{g} \mathrm{AT} \mathrm{L} \mathrm{L}^{-1}\right)$ & 3.86 & 3.52 & $3.11-4.58$ & $3.04-4.58$ & 9.19 & 9.08 & 38.28 & 44.80 \\
\hline $\operatorname{MalA}\left(\mathrm{g} \mathrm{L}^{-1}\right)$ & 2.80 & 1.87 & $2.20-3.40$ & $1.32-2.33$ & 10.47 & 14.49 & 42.93 & 53.43 \\
\hline $\operatorname{TarA}\left(\mathrm{g} \mathrm{L}^{-1}\right)$ & 6.22 & 5.92 & $5.82-6.93$ & $5.53-6.51$ & 3.54 & 3.68 & 17.68 & 16.89 \\
\hline YAN (mg L L $\left.\mathbf{L}^{-1}\right)$ & 118.26 & 104.18 & $80.02-195.15$ & $73.36-153.85$ & 15.74 & 17.42 & 97.64 & 76.74 \\
\hline TAnt (mg L $\left.\mathbf{L}^{-1}\right)$ & 896.48 & 930.20 & $646.25-1238.84$ & 731.41-1137.48 & 12.99 & 9.79 & 66.09 & 43.68 \\
\hline EAnt $\left(\mathrm{mg} \mathrm{L}^{-1}\right)$ & 347.77 & 343.84 & $251.31-437.26$ & $261.52-444.33$ & 12.33 & 12.71 & 53.54 & 53.39 \\
\hline $\mathbf{T P}\left(\mathrm{mg} \mathrm{L}^{-1}\right)$ & 1149.11 & 1144.31 & $949.20-1474.36$ & $870.25-1400.45$ & 9.01 & 9.08 & 45.73 & 46.31 \\
\hline
\end{tabular}

$\mathrm{CV}$, Coefficient of variation; Spread, the range divided by the median, expressed as a percentage; TSS, Total Soluble Solids; TA, Titratable Acidity; MalA, Malic Acid concentration; TarA, Tartaric Acid concentration; YAN, Yeast Assimilable Nitrogen; TAnt, Total Anthocyanins; EAnt, Extractable Anthocyanins; TP, Total Phenolics 
Table 2 Evaluation of the agronomical significance the classes obtained through ANOVA from NDVI, EC $C_{a}$, $\mathrm{BN}$ and their combinations

\begin{tabular}{|c|c|c|c|c|c|c|c|c|c|c|c|c|c|c|}
\hline & \multicolumn{2}{|c|}{ NDVI } & \multicolumn{2}{|c|}{$\mathbf{E C}_{\mathbf{a}}$} & \multicolumn{2}{|c|}{$\mathbf{B N}$} & \multicolumn{2}{|c|}{$\mathbf{E C}_{\mathrm{a}}+\mathrm{BN}$} & \multicolumn{2}{|c|}{$\mathbf{N D V I}+\mathrm{EC}_{\mathrm{a}}$} & \multicolumn{2}{|c|}{ NDVI+BN } & \multicolumn{2}{|c|}{$\mathbf{N D V I}+\mathrm{EC}_{\mathrm{a}}+\mathrm{BN}$} \\
\hline & 2010 & 2011 & 2010 & 2011 & 2010 & 2011 & 2010 & 2011 & 2010 & 2011 & 2010 & 2011 & 2010 & 2011 \\
\hline Yield (kg) & * & $n s$ & ns & ns & * & $n s$ & * & * & * & * & * & * & * & * \\
\hline BW (g) & * & ns & $n s$ & ns & * & ns & * & * & * & ns & * & * & * & * \\
\hline TSS ( ${ }^{\circ}$ Brix) & ns & * & ns & ns & $n s$ & $n s$ & * & ns & $n s$ & * & ns & * & * & * \\
\hline pH & * & * & ns & ns & * & $n s$ & * & ns & * & * & * & * & * & * \\
\hline $\mathrm{TA}\left(\mathrm{g} \mathrm{AT} \mathrm{L}^{-1}\right)$ & * & $n s$ & $n s$ & ns & ns & ns & * & * & ns & * & * & $n s$ & ns & * \\
\hline $\operatorname{MalA}\left(\mathrm{g} \mathrm{L}^{-1}\right)$ & ns & * & $n s$ & $n s$ & $n s$ & $n s$ & ns & * & ns & $n s$ & ns & ns & $n s$ & ns \\
\hline $\operatorname{Tar} A\left(g^{-1}\right)$ & ns & $n s$ & ns & ns & ns & $n s$ & ns & * & $n s$ & ns & ns & ns & ns & $n s$ \\
\hline YAN $\left(\mathrm{mg} \mathrm{L}^{-\mathbf{1}}\right)$ & ns & * & ns & ns & ns & * & ns & * & ns & ns & ns & * & $n s$ & * \\
\hline TAnt $\left(\mathrm{mg} \mathrm{L}^{-1}\right)$ & * & $n s$ & $n s$ & ns & $n s$ & * & * & * & $n s$ & ns & * & * & * & * \\
\hline EAnt $\left(m g L^{-1}\right)$ & ns & ns & ns & ns & ns & $n s$ & * & ns & ns & ns & ns & * & * & * \\
\hline $\mathbf{T P}\left(\mathrm{mg} \mathrm{L}^{-1}\right)$ & * & $n s$ & $n s$ & ns & $n s$ & $n s$ & ns & * & $n s$ & ns & * & * & * & $n s$ \\
\hline TOTAL Q & 4 & 4 & 0 & 0 & 1 & 2 & 4 & 6 & 1 & 3 & 4 & 6 & 5 & 6 \\
\hline TOTAL & 6 & 4 & 0 & 0 & 3 & 2 & 6 & 8 & 3 & 4 & 6 & 8 & 7 & 8 \\
\hline
\end{tabular}

NDVI, Normalized Difference Vegetation Index; BN, Bunch number; $\mathrm{EC}_{\mathrm{a}}$, Soil apparent Electric Conductivity; BW, Berry Weight; TSS, Total Soluble Solids; TA, Titratable Acidity; MalA, Malic Acid concentration; TarA, Tartaric Acid concentration; YAN, Yeast Assimilable Nitrogen; TAnt, Total Anthocyanins; EAnt, Extractable Anthocyanins; TP, Total Phenolics; TOTAL Q: number of berry composition variables for which significant differences appeared; TOTAL number of variables for which significant differences appeared;* Significant differences between classes $(P<0.05)$; ns, non-significant $(P>0.05)$. The number of classes was always 3, except for NDVI+BN in 2011 and for $N D V I+E C_{a}+B N$ in 2010 and 2011, for which it was 2. 
Table 3 Evaluation of the significance of the classes obtained from NDVI, ECa, BN and their combinations to delineate zones with different grape composition using MANOVA

\begin{tabular}{|c|c|c|c|c|c|c|}
\hline & \multirow[b]{2}{*}{$d f$} & \multirow[b]{2}{*}{$\begin{array}{c}D f \\
\text { error }\end{array}$} & \multicolumn{2}{|c|}{2010} & \multicolumn{2}{|r|}{2011} \\
\hline & & & $F$ & $P$ & $\boldsymbol{F}$ & $P$ \\
\hline NDVI & 18 & 98 & 2.343 & 0.004 & 3.410 & $<0.001$ \\
\hline $\mathbf{E C}_{\mathbf{a}}$ & 18 & 98 & 1.305 & 0.202 & 0.832 & 0.659 \\
\hline BN & 18 & 98 & 1.164 & 0.306 & 0.907 & 0.572 \\
\hline $\mathrm{ECa}+\mathrm{BN}$ & 18 & 98 & 2.988 & 0.006 & 2.440 & 0.003 \\
\hline $\mathrm{NDVI}+\mathrm{EC}_{\mathrm{a}}$ & 18 & 98 & 2.032 & 0.014 & 1.020 & 0.445 \\
\hline NDVI+BN & 9 & 50 & 2.622 & 0.014 & 4.989 & $<0.001$ \\
\hline $\mathrm{NDVI}+\mathrm{EC}_{\mathrm{a}}+\mathrm{BN}$ & 18 & 98 & 2.200 & 0.038 & 2.784 & 0.010 \\
\hline
\end{tabular}

NDVI, Normalized Difference Vegetation Index; BN, Bunch number; $\mathrm{EC}_{\mathrm{a}}$, Soil apparent Electric Conductivity; $d f$; degrees of Freedom; F, Fisher's F-ratio; $P$, P-value. The number of classes was always 3, except for NDVI+BN in 2011 and for NDVI+EC + a 
FIGURE CAPTIONS

Figure 1 Relationship between NDVI and the sum of shoot cross-sectional area (SCSA)

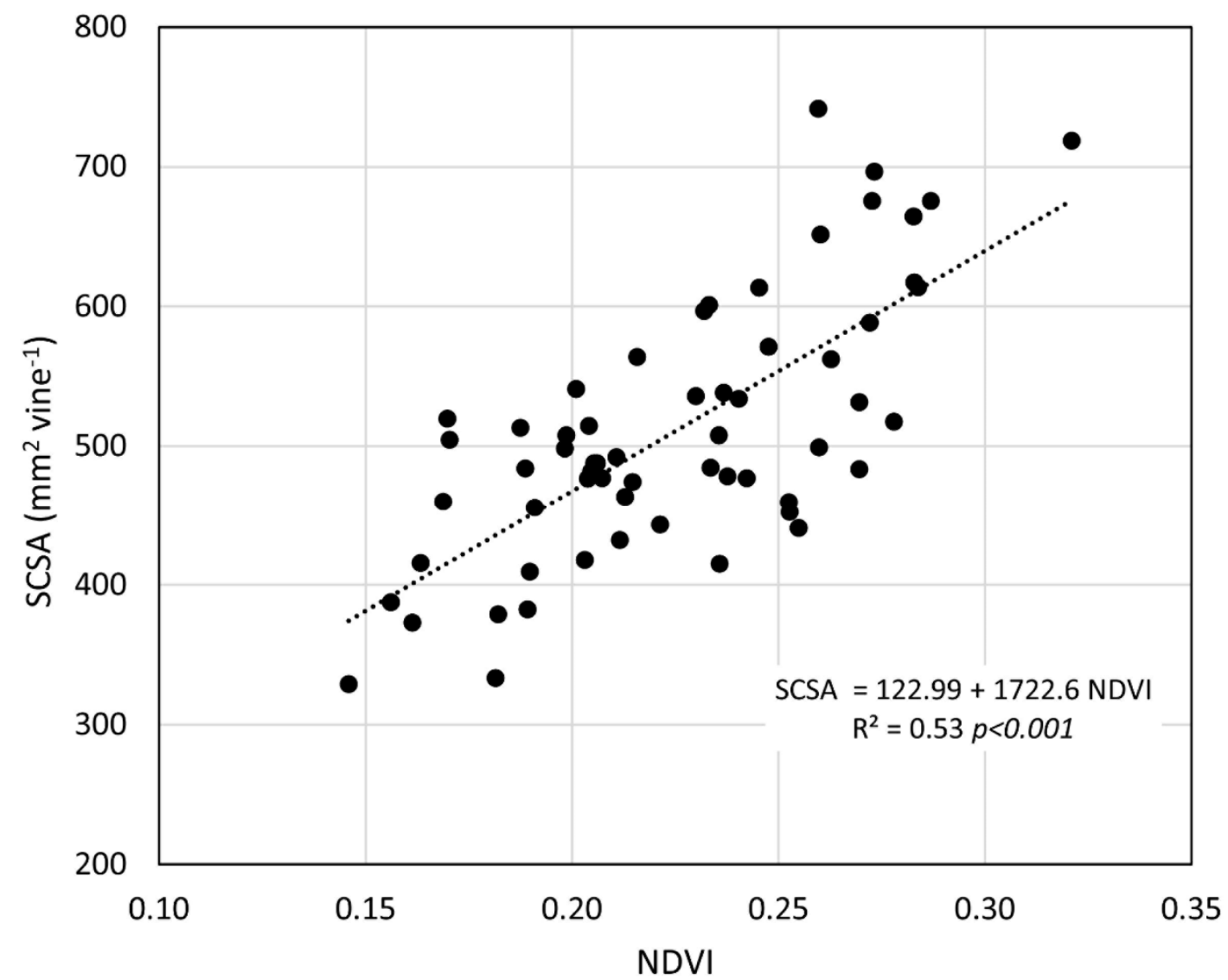




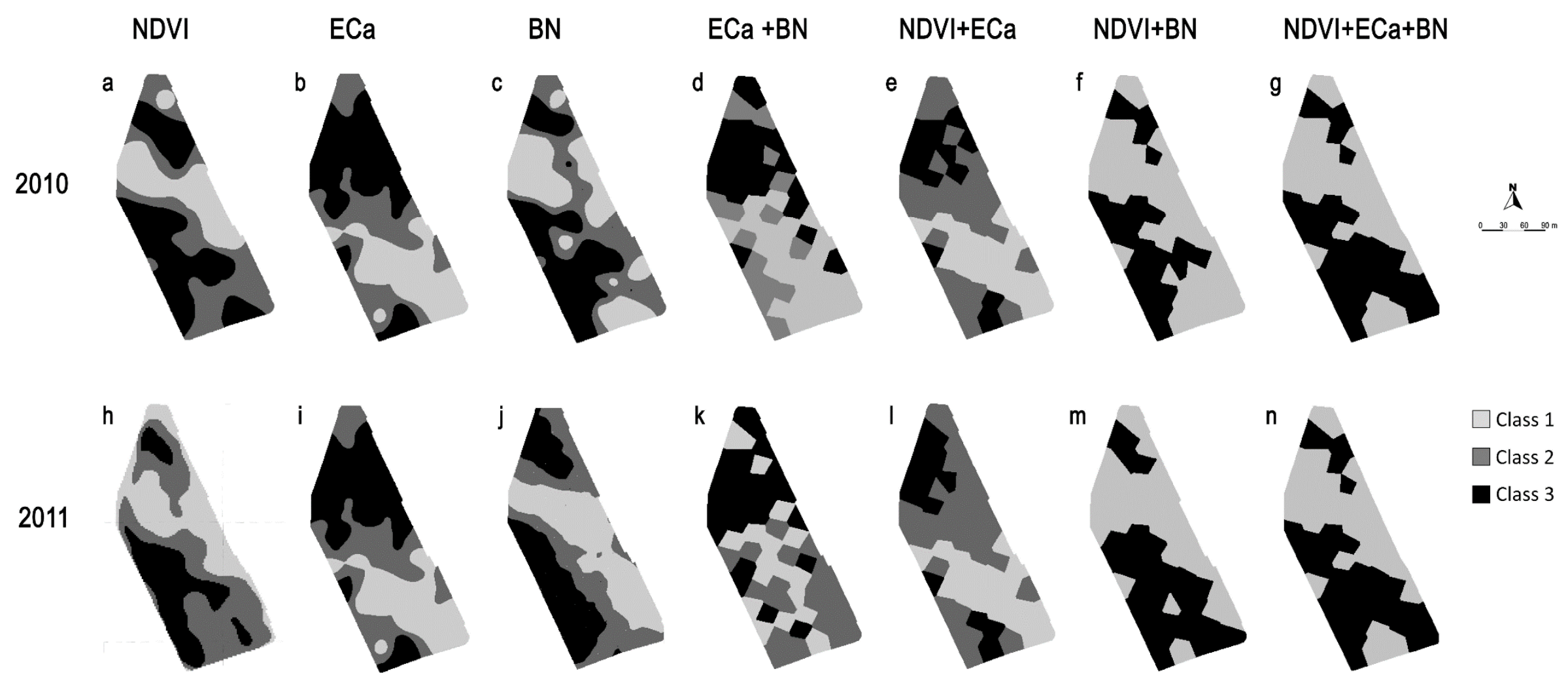

Figure 2 Maps of zones delineated using NDVI, EC a BN and their in 2010 and 2011 